\title{
Análise do discurso da tomada de posse
}

\author{
Zélia Maria Viana Paim*
}

Resumo: Este artigo propõe algumas reflexões sobre o "discurso da descoberta". Para tanto, elege-se como objeto de análise o Diário da Primeira Viagem, escrito por Cristóvão Colombo em 1493, e a Carta, de Pero Vaz de Caminha, escrita em 1500. A partir da análise do relato de Colombo e de Caminha, perguntamo-nos como se constituiu o "ritual da tomada de posse", tomando Pêcheux ([1977], 1988), Orlandi (2003), Connerton (1999) e Eliade (1993) como base teórica.

Palavras-chave: Discurso; Ritual; Sentido.

Neste artigo, apresentamos parte do percurso de nossa tese de doutorado intitulada $\mathbf{O}$ movimento dos sentidos: de utopia à conversão, reflexão constituída a partir de duas áreas de conhecimento que aqui se complementam, Análise de Discurso e História das Ideias. A partir da análise do relato de Colombo e Caminha, respectivamente em Diário da Primeira Viagem e na Carta, perguntamo-nos como se constituiu o ritual da tomada de posse, elegendo os seguintes estudiosos: Pêcheux ([1977], 1988), Orlandi (2003), Connerton (1999) e Eliade (1993) como base teórica para responder à questão proposta.

$\mathrm{Na}$ época dos descobrimentos, portugueses e espanhóis na sua maioria recorriam a questionários oficiais para noticiar as novas descobertas ou para entabular o contato necessário às atividades de expansão e de domínio. Muitas das ações dos comandantes das naus remetem às questões propostas pelo questionário oficial, mas tanto no relato de Colombo como no de Caminha observamos a primeira dessemelhança, que estamos chamando de "episódio da tomada de posse". No relato de Colombo, esse episódio se articula ao modo de um cerimonial, no instante mesmo da abordagem da terra, como podemos observar no seguinte trecho do Diário da Primeira Viagem:

O Almirante empunhou a bandeira real e os comandantes as duas bandeiras da Cruz Verde, que o Almirante levava como um emblema em todos os navios, com um F e um Y: por cima de cada letra, a respectiva coroa, a primeira feita de um cabo da cruz e a segunda do outro. Ao desembarcar viram árvores muito verdes, muitas águas e frutas de várias espécies. O Almirante chamou os dois comandantes e

* Doutora em Letras - Estudos Linguísticos, pelo PPGL/UFSM, sob orientação da Prof. ${ }^{a}$ Dr. Amanda Eloina Scherer. E-mail: zeliamvp@hotmail.com 
demais acompanhantes, e Rodrigo de Escovedo, escrivão de toda a armada, e Rodrigo Sánchez de Segovia [inspetor a serviço de El-Rei], e que the dessem por fé e testemunho como ele, diante de todos, tomava, como de fato tomou, posse da dita ilha em nome de El-Rei e da Rainha, seus soberanos, fazendo os protestos que requeriam, como mais extensamente se descreve nos testemunhos que ali procederam por escrito. Logo viram-se cercados por vários habitantes da terra (COLOMBO [1492], 1998, p. 51-52). [grifos nossos]

O sujeito do discurso narra os passos do Almirante, seu outro, a personagem do feito épico, descrevendo a terra em primeiro lugar para, a seguir, tomar posse. Contudo, é somente depois dessa tomada de posse que percebe os habitantes. Entende-se que esse gesto de ignorar os habitantes da terra demonstra que, desde o início, esses são homens sem nenhuma importância enquanto tais para a história dos descobrimentos, sob a ótica do europeu. A cerimônia da tomada de posse é registrada oficialmente, "mais extensamente" num livro a parte por representantes da Coroa espanhola. Colombo toma posse da terra tendo por testemunha autorizada "dois comandantes e demais acompanhantes", um "escrivão" e um "inspetor". Do mesmo modo, a presença onisciente da Igreja se configura nas palavras de Colombo: "a primeira feita de um cabo da cruz e a segunda do outro". No "encontro" com o homem do Novo Mundo, realidade e história estavam em algum outro lugar, corporificados por homens europeus.

Já o relato de Caminha não descreve o "ritual da tomada de posse". Entende-se que este se estabelece de maneira diversa: no último dia da estadia da armada de Cabral no litoral da terra achada, no "episódio de chantar a cruz". A este ato simbólico de tomada de posse em nome da Igreja e da Coroa, seguese o "episódio da segunda missa". Esse foi um longo cerimonial cujo início é descrito desse modo, por Caminha, na Carta:

Hoje, que é sexta-feira, $1^{\circ}$ de maio, saímos pela manhã, para terra com nossa bandeira. Fomos desembarcar acima do rio, para o sul, onde nos pareceu que seria melhor chantar a cruz, para melhor ser vista. Ali assinou o capitão onde fizesse a cova para melhor chantar. Enquanto a ficaram fazendo, ele, como todos nós outros, fomos abaixo do rio, onde ela estava. Trouxemo-la dali com esses religiosos e sacerdotes, cantando [à] maneira de procissão. Alguns deles já estavam aí, obra de 70 ou 80. Quando nos viram assim foram meter-se debaixo dela [para] ajudar-nos. [...] Chantada a cruz, com as armas e divisa de Vossa Alteza, que primeiro lhe pregaram, armaram [um] altar ao pé dela. Ali disse missa o padre Henrique, a qual foi cantada e oficiada por esses já ditos (CAMINHA, [1817], 2001, p. 110-111).

No relato de Caminha, há a presença dos homens da terra junto aos portugueses, participando da cerimônia do carregamento da cruz e da 
procissão. No entanto, ao enunciar "nós", Caminha refere-se ao "capitão", aos "navegadores", aos "religiosos", aos "sacerdotes", que estão agindo coletivamente sob uma mesma bandeira. O "nós" reúne os sujeitos de dois discursos - o escrivão Caminha e o padre Henrique -, o do Estado e o da Igreja. Os indígenas, "alguns deles", "70 ou 80", embora ajudem a carregar a cruz, não pertencem a essa comunidade cristã nem são sujeitos do discurso. Observa-se também que "chantar" origina-se do latim plantare, que deu origem a "plantar"1. Caminha, ao enunciá-la, remete ao imbricamento desses dois discursos referidos, entendidos como o "discurso do enraizamento do colonialismo" e o "da semeadura do cristianismo", constituindo a terra descoberta como colônia cristã.

Segundo Eliade (1993, p. 23), os mares desconhecidos em que navegador algum ousou aventurar-se correspondem a um modelo mítico, isto é, "todas as regiões selvagens, incultas estão consubstanciadas no caos"; participam, ainda, da "modalidade indiferenciada, informe, anterior à Criação". É por isso que quando tomavam posse de um desses territórios, ou seja, quando começavam a explorar, realizavam ritos que repetiam simbolicamente o ato da Criação. Desse modo, a zona inculta é primeiro "cosmificada". Espanhóis e portugueses apropriavam-se em nome de Cristo das ilhas e continentes que descobriam e conquistavam. A instalação da Cruz equivalia a uma "justificação" e à "consagração" da região, a um "novo nascimento", repetindo assim "o batismo, o ato da criação", tal como esclarece Eliade (Ibid., p. 24). Qualquer território ocupado com vistas à fixação ou à utilização como "espaço vital" era previamente transformado de "caos" em "cosmos"; isto é, por um ritual, era-lhe conferida uma "forma" que o tornava "real" (Ibid., p. 24).

Para Connerton (1999, p. 61), o ritual é explicado como uma "forma de representação simbólica". Conforme o autor, tanto o ritual como o mito podem ser vistos como textos simbólicos coletivos. No entanto, salienta que "interpretar o ritual como um meio simbólico que diz aquilo que pode ser dito por outros meios e, em particular, sob a forma de mito, é ignorar aquilo que o ritual tem de diferente" (Ibid., p. 61). A forma ritual não é apenas a alternativa de exprimir certas crenças, mas certas coisas só podem ser expressas através do ritual. $\mathrm{O}$ ritual e o mito diferem estruturalmente, pelo menos em um aspecto fundamental: "a existência de um elemento de invariância na estrutura do ritual que não se encontra presente no mito", afirma Connerton (Ibid., p. 62).

Para esse mesmo autor, em comparação com os mitos, a estrutura dos rituais tem significativamente menos potencial de variação. É verdade que todos os rituais tiveram que ser inventados em um dado momento, podendo os pormenores de sua articulação desenvolver ou variar em conteúdo e

${ }^{1}$ Definições a partir do Novo Dicionário Aurélio (1975). 
importância com a passagem do tempo. Todavia, continua a existir um potencial de invariância incorporada nos ritos, em virtude do fato, intrínseco à natureza dos rituais, de "esses especificarem a relação que prevalece entre a execução do ritual e aquilo que os participantes estão a executar" (Connerton, 1999, p. 65). Esta tendência para a invariância resulta da forma particular do discurso ritual, que funciona poderosamente como "instrumento mnemônico" (Ibid., p. 66). No ritual, o discurso e o gesto constituem a sua marca distintiva, facilmente predizível e repetível de um ato para o seguinte e de uma ocasião ritual para a seguinte.

$\mathrm{Na}$ teoria discursiva, acrescenta-se à noção de ritual a falha, como lhe sendo constitutiva. Para Pêcheux ([1977], 1988, p. 301), "não há ritual sem falhas, enfraquecimento e brechas". A metáfora, considerada restritivamente como "uma palavra por outra", é o ponto em que um ritual se quebra, porque possibilita o equívoco, daí a falha estruturante de qualquer dizer, acrescenta Pêcheux. As falhas do ritual, explica Pêcheux, são "formas de aparição fugidias de alguma coisa 'de uma outra ordem', vitórias ínfimas que, no tempo de um relâmpago, colocam em xeque a ideologia dominante tirando partido de seu desequilíbrio" (Ibid., p. 301).

A metáfora, segundo Orlandi (2003, p. 79), é "constitutiva do processo de constituição mesma do sujeito". Para essa autora, a "metáfora" é entendida como "transferência de sentido"; nesse movimento, o ponto de partida e o ponto de chegada, através de deslizamentos de sentidos, são completamente diferentes. Essa diferença se sustenta em um mesmo ponto que desliza do ponto de partida ao ponto de chegada, levando a autora citada a afirmar que "há um mesmo nessa diferença" (Ibid., p. 79). Entendemos que o movimento que se dá para a produção de sentidos, os deslizes, as derivas, é próprio às condições de produção em que estão imersos.

Nessa perspectiva, o espaço foi constituído com sentidos cristalizados e autorizados pelo ato de fé e pelo chantar da cruz. Desse modo, foi alçado à propriedade das coroas ibéricas como espaço cristão. A análise nos permitiu ir do ritual a metáfora e, na conclusão deste estudo, deu margem a outra questão: como se constituiu essa descoberta do outro, cujo sentido retorna ao europeu?

\section{Referências}

CAMINHA, Pero Vaz de. [1817]. Carta de Pero Vaz de Caminha. In: MACHADO, Janaína; FIGUEIREDO, Luis (orgs.). Brasil 500: quarenta documentos. Brasília: Universidade de Brasília; São Paulo: Imprensa Oficial do Estado de São Paulo, 2001.

COLOMBO, Cristóvão. [1492]. Diários da descoberta da América: as quatro viagens e o testamento. Traduzido por M. Persson. Porto Alegre: L\&PM, 1998.

CONNERTON, Paul. Como as sociedades recordam. 2.ed. Traduzido por M. M. Rocha. Oeiras: Celta, 1999. 
ELIADE, Mircea. O mito do eterno retorno: arquétipos e repetição. Traduzido por M. Torres. Lisboa: Edições 70, 1993.

ORLANDI, Eni Puccinelli. Análise de discurso: princípios e procedimentos. 5.ed. Campinas: Pontes, 2003.

PÊCHEUX, Michel [1977]. Semântica e discurso: uma crítica à afirmação do óbvio. 2.ed. Traduzido por E. P. Orlandi. Campinas: Unicamp, 1988. 